\title{
RFID And Supply Chain Management: An Assessment Of Its Economic, Technical, And Productive Viability In Global Operations
}

Anthony Narsing, (E-mail: anarsing@mail.maconstate.edu), Macon State College

\begin{abstract}
The integration of Radio Frequency Identification (RFID) systems within a company's supply chain offers an abundance of economic and productive capabilities. RFIDs permit an organization's supply chain to have increased product visibility, reduction of stock, trim warehouse costs, eliminate stock errors, reduce theft and shrinkage and allow them to update their logistics and inventory databases with real-time information. The technical capabilities and limitations of RFIDs are examined. Suppliers and retailers must create solid alliances to build an RFID network, which must support both technical and operational information needs. This is a necessary and sufficient condition for integrating RFID within their respective supply chains. While cost is identified as the predominant factor inhibiting progress in RFID tagging at the product unit level, the future remains very promising for rapid gains in RFID development as long as technology continues to advance through increased research and development initiatives.
\end{abstract}

\section{INTRODUCTION}

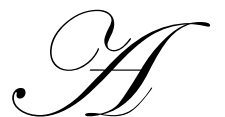

n essential ingredient for an effective and efficiently managed supply chain includes accurate, realtime information about products within the chain. The integration of Radio Frequency Identification (RFID) systems within a company's supply chain offers an abundance of economic and productive capabilities. An RFID is a "white" tag with an imbedded microchip containing product information which can be accessed by a receiver using radio frequencies. The "white" tag is affixed to the product at the pallet level while still at the warehouse prior to shipment. With RFID systems, companies would have increased product visibility, reduce out-of-stock items, trim warehouse costs, eliminate stock errors, reduce theft and shrinkage and allow companies to regularly update their logistics and inventory databases. Several pilot studies are underway globally to study RFID system application and its integration within existing ERP systems (Kinsella, 2003, Sullivan, 2005 and Weisman, 2005). Most companies are taking a cautious approach and initially focusing their study of RFIDs at the pallet level before progressing towards each product unit stored in a box (Hall, 2004 and Bednarz, 2004).

RFID, albeit not a new technology but rather an evolving one, possesses tremendous opportunities for companies eager to sustain a global competitive advantage by allowing them to move from a forecast to a demand driven network. RFIDs integration within the supply chain presents a mix of complexities coupled with high expenditures, as is the case with most work-in-progress technologies. According to Hickey (2003), expenditures for RFID hardware used in supporting Supply Chain Management (SCM) applications were estimated at \$89 Million in 2002 and expected to increase by $38 \%$ by the year 2007. Meanwhile, SCM software applications which integrate RFIDs technology were projected to reach an estimated $\$ 448.4$ Million by the same period. In comparison, global expenditures for RFID systems were \$965 Million in 2002 (Hickey, 2003).

Current applications for RFID systems are in the field of industrial/manufacturing and transportation/distribution. Emerging growth areas now include retail, health care, and commercial services. The top 
five growing RFID application areas in order of ascending growth include: baggage handling, retail item tracking, point-of-sale systems, real-time location, and Supply Chain Management (Hickey, 2003). The world's largest retailer, Wal-Mart is taking a gigantic step by requiring its top 100 suppliers to adapt into their current business operations its RFID/ Electronic product code program by January, 1, 2005 (Kinsella, 2003). At this point, Wal-Mart is only concerned with identifying products at the pallet level, rather than at the product unit level. The Department of Defense (DOD) is requiring the same degree of commitment from its suppliers by following Wal-Mart's lead, except that they are pursuing a more aggressive position beyond the pallet level incorporating. That is, requiring not only pallets to be tagged but also items in individual boxes by January 1, 2005 (Tegtmeier, 2004).

In this paper, the author will investigate the importance of this continually evolving RFID technology and its impact on long-term corporate strategies, global markets, and its potential role for sustained corporate growth and profitability. In the first section, the author will explore its technical capabilities and limitations, while the second section will examine the economic and productive viability followed by examples of applications. The last section will end with discussion of findings and followed by the conclusion.

\section{TECHNICAL CAPABILITIES AND LIMITATIONS}

RFID tags consist of two components: a silicon microchip and an antenna. The chip is able to perform two functions: receive and transmit data. Tags can be classified as active, semi-active or passive. Passive tags are by far the simplest and least expensive which makes them economically attractive to users. They have no power source as they obtain energy from the radio frequency field emitted by the reader. Semi-active or passive tags have an energy source built onto the micro-chip hence adding to its cost; however, they have the ability to provide broad range coverage and to also read information from sensors (Lawrence, 2004). Exhibit 1, illustrates a typical application.

Exhibit 1: Typical RFID Application (Source: Fowler, 2003)

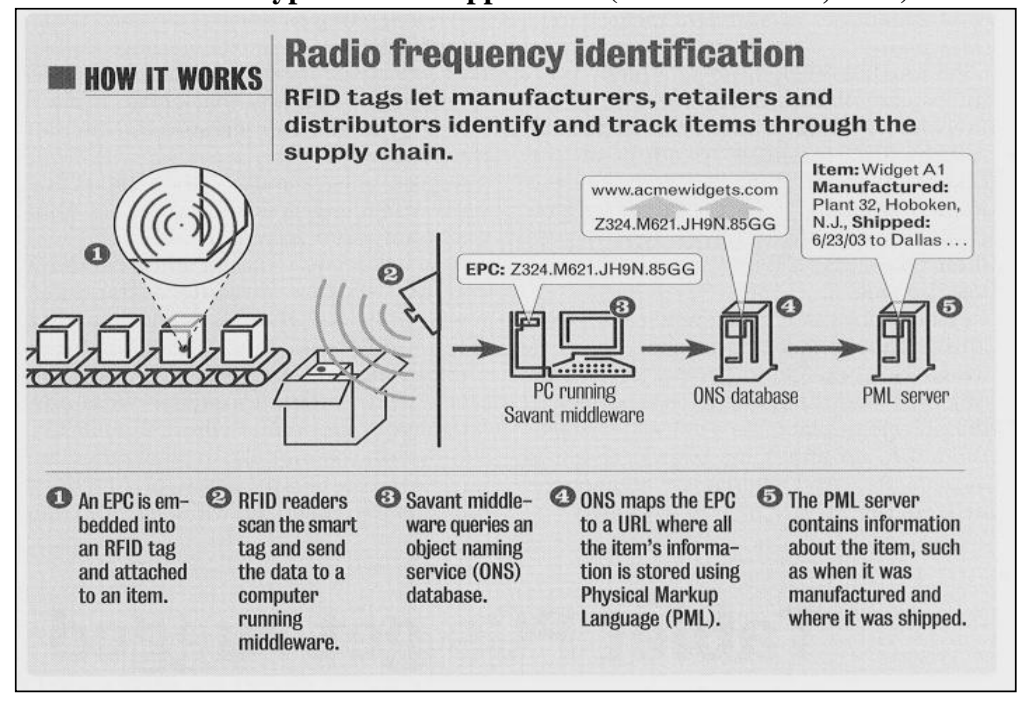

A typical operation of an RFID occurs when a reader uses a coiled antenna to create a magnetic field which reaches the chip on a passive tag regardless of its position or orientation on the shelf or floor. The microchip is energized by the radio frequency field and subsequently transmits data via its antenna containing product information such as batch number, production date and so forth.

Multiple tags can be accessed by a reader which can vary from a hand-held device to a stationary tunnel like device able to scan boxes on a conveyance system which can be either a roller or belt conveyor systems. A customer could be supplied with real-time information regarding stock,

in-transit goods and product specification such as the date of manufacture. The reader must be within acceptable distance to reduce interference. Readers are strategically positioned at various locations such as by dock doors, pallet racks, conveyors or check out lanes (Kinsella, 2003). Broadcasting frequencies can take place at varying levels. Low frequency application can range from $3 \mathrm{KHZ}$ to $300 \mathrm{KHZ}$ while high frequency applications range from $3 \mathrm{MHZ}$ to 30 MHZ (Bednarz, 2002). As with many technologies, there are always limitations to their wide-scale implementations in existing business processes. RFID technology has a number of operational factors which can adversely impact its efficient operation such as RFID command language, the presence of moisture, inclement weather, radiation, invisible RF interference (i.e., WLANs), attenuation, reflection and refraction of radio waves, the material to which a tag is affixed and to some extent building material content (Goldman, A. and Crawford, K., 2004). 
Outside of these inhibiting factors, operating standards remains a contentious issue. For instance, countries that use different operating standards create tremendous barriers to global integration. Regulatory laws in Asia, Europe and North America are specific regarding frequency and power requirements (Bednarz, 2003). For instance, Asia uses $950 \mathrm{MHZ}$, Europe uses $869 \mathrm{MHZ}$ and North America uses $915 \mathrm{MHZ}$. Japan refuses to allow UHF which is the frequency of choice in the United States. Interestingly enough, Gillette had purchased 500 million tags at less than 10 cents; unfortunately, they quickly found out that these tags were not compliant with European standards. They are currently testing tags from Phillips to determine their applicability overseas. EPCglobal which is a joint venture between European Article Number (EAN) and the Uniform Code Council (UPC) was established on November 1, 2003. It funded by suppliers and users whose main purpose is to develop standards for Electronic Product Code (EPC) to support the RFID infrastructure.

\section{ECONOMIC VIABILITY}

Most companies are reluctant to spend scarce operating resources particularly since RFIDs is still in its evolutionary stage. The high cost of RFID systems remain a significant factor against wide-spread implementation. For instance, smart labels can range from $\$ 0.40$ to $\$ 1.00$ each if purchased in bulk; otherwise, cost would be considerably higher for smaller orders. Gillette spent under $\$ 1.00$ when it ordered 500 million passive tags. Boston based Yankee Group estimate savings from $\$ 200$ to $\$ 400$ billion if companies align their business processes with RFID systems. To realize this level of savings, top suppliers from Wal-Mart and DOD must consider spending anywhere from \$3 to \$35 million on EPC RFID in 2004 (Speigel, 2004). P\&G estimated that it costs \$2 million to outfit its first warehouse (includes hardware, software, integration and business process changes) and $\$ 1$ million for additional warehouses. Software and integration costs, while staggering, can vary among vendors. Marks \& Spencer spent $\$ 1$ million in software development and integration costs when it implemented its initial RFID system for its food service business (Kinsella, 2003).

The biggest push for RFID adoption spearheaded by both Wal-Mart and the DOD promises to inflict financial strain on its suppliers to comply and deploy RFID infrastructure within existing ERP systems. Noncompliance by suppliers could mean loss of contracts or inability to compete for future contracts. DOD alone has an estimated 43,000 suppliers and must manage in excess of 4.5 million stock part numbers world-wide. With RFID in place, the DOD will benefit from increased asset visibility, improved tracking and tracing, reduction in theft and shrinkage, increased field maintenance and inventory management. A reported $\$ 1.2$ Billion discrepancy was noted by the General Accounting Office between items shipped and those used by military personnel in Iraq (Tegtmeier, 2004). Wal-Mart and the DOD further believe that such cooperation will enhance Supply Chain Management programs at respective companies and, in the long-term, produce greater savings for everyone. According to Speigel (2004), 40\% of Wal-Mart's invoices are associated with varying degrees of inventory reduction. It is expected that RFID, together with realigned business process should reduce inventory shortage. That is, items whose count on the pallets differs from the time it leaves the distribution centres and when it reaches its final destination point (i.e. at store docks).

Other companies have begun pilot trials: $\mathrm{P} \& \mathrm{G}$, Gillette, Unilever, Altria and European retailers Woolworth's and Marks\&Spencer (Kinsella, 2003). Marks \& Spencer revealed estimated savings between 50\%-60\% savings in materials receiving labor by integrating RFID and making changes to its existing business processes. These savings were a direct result of embedding its reusable trays, dollies and cages used to carry refrigerated foods were with 3.5 million tags. At that time, the large order of RFID tags by Marks \& Spencer created a buzz within the retail industry (Bednarz, 2002). Woolworth's motivation towards RFID system integration is to achieve important strategic goals for the company. Such goals included maximization of real-time security, increased visibility in the chain and improved control over asset management in the supply chain (London, 2003). With its RFID initiatives firmly established, Woolworth projects a $0.25 \%$ sales increase from a reduction in stock-outs by initially affixing tags to its dollies and roll cages. Gillette, which began tagging its new high-end Venus razors at the pallet and case level, is so marveled by its initial success that they intend on expanding their tagging to include the unit level in 2005. They estimated that the cost of theft reduction associated with its high-end razors will far outweigh initial investments in RFID systems.

Boeing and FEDEX, through a joint effort recently conducted a pilot study where they tested "13.56 MHZ passive smart labels" with 10 Kbytes of memory and a built-in RFID to see how they would react in adverse 
conditions when stored on a FEDEX MD-10. These smart tags were placed on the flight deck, in the avionics compartment, cargo area and wheel wells areas where they were monitored for electromagnetic interference and memory corruption (Tegtmeier, 2004). The plane operated over a period of 90 days with an average of 18 hours per flight per day. The results were very encouraging as the "smart labels" revealed no indication of electromagnetic interference or corruption to the information programmed onto the micro-chip. As a follow-up, Boeing and FEDEX plan to test these passive tags at 915 MHZ UHF which is the North American Standard in frequency transmission to examine issues concerning range, memory loss and electromagnetism.

Both Wal-Mart and the DOD have stipulated conditions under which suppliers must adopt RFID infrastructure to its existing ERP systems, which of course, will require changes to their business processes which would all entail significant capital investments. Essentially, organizations would require new software, hardware and definite re-engineering of their process operations. Given the extensive capital outlay, only $20.2 \%$ opted for early adoption, $42.7 \%$ for medium adoption and $37.1 \%$ accounted for late adopters (Aberdeen Group). While the benefits to adoption were previously outlined, what appears to be certain is that RFID technology has not sufficiently progressed where results from Supply Chain Management, asset management and inventory control can produce measurable results. Exhibit 2 provides a relation between value and feasibility to a firm. As shown, RFID systems can provide high value to the firm as it strives to achieve total supply chain visibility; unfortunately, its feasibility becomes more difficult.

Exhibit 2: RFID Value and Its Feasibility (Source: Byrne, 2004)

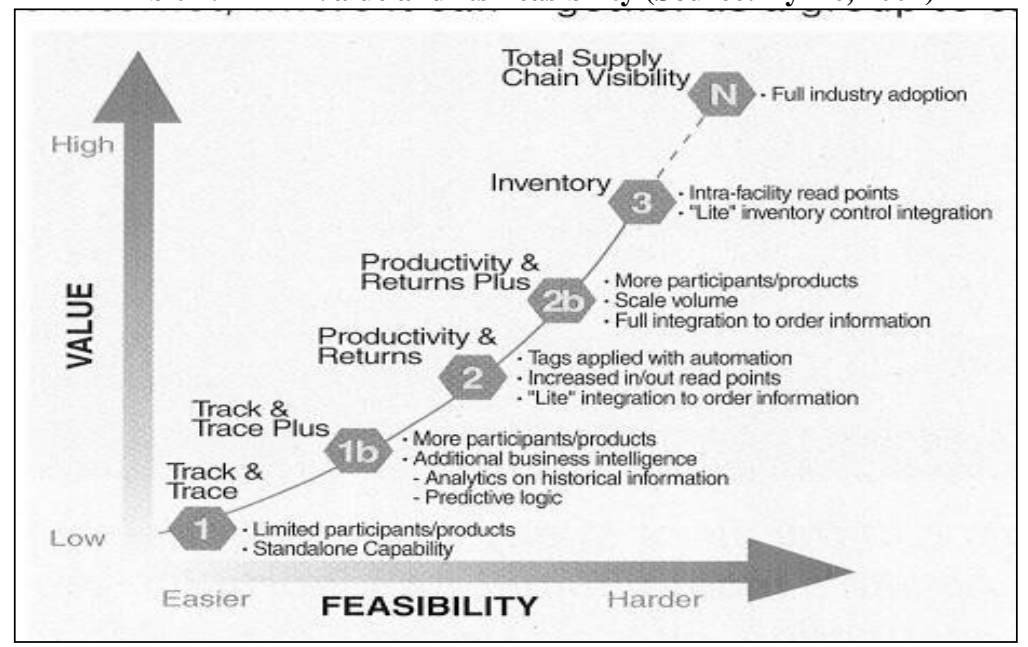

Currently, most organizations conducting RFID pilot studies are concentrating their efforts by tagging at the pallet and box level. Gillette's performs its entire R\&D in-house in the development of RFID, while others rely on outsourcing to third-party subcontractors. The January 1 , 2005 deadline set by Wal-Mart for its suppliers to be RFID compliant already encountered setbacks and delays. In recognition of the problems encountered by its suppliers, Wal-Mart decided to relax its January 2005 deadline. Currently, WalMart's 137 lead-off suppliers are only able to tag 65 percent of their products while laggards are tagging one to two percent (Bednarz, 2004 and Weisman, 2005). Among its top 100 suppliers, an estimated 30 percent anticipate reaching full scale implementation by January (Bednarz, 2004) while only two of their suppliers were permitted an extension to the January 2005 RFID adoption deadline (Weisman, 2005). The remaining 70 percent are reluctant and somewhat skeptical of RFID adoption because of concerns attributed to cost, unstable technology and lack of technical support from Wal-Mart. Instead they have relied on the "slap and ship" approach to cut costs using third party sub-contractors who are responsible for tagging at the distribution centre (Bednarz, 2004 and Weisman, 2005). Wal-Mart prefers that its suppliers integrate RFID technology early in the manufacturing process.

Cost and technology are identified as the dominant factors affecting compliance among RFID adopters (Bednarz, 2004, Hall, 2004, Sullivan, 2005 and Weisman, 2005). This should come as no surprise because leading experts have previously predicted these factors. First, countries are still grappling with establishing operating standards. Until there is some form of agreement between countries, it is going to be impossible for global interaction which virtually renders RFID systems useless overseas. Secondly, the Class 1 passive RFID tags that are used in most pilot studies have limited capacity for storing EPC information. Class 3 or 4 RFID tags include a battery which provides increased storage capacity and signal strength permitting them to function reliably under real-world settings (Hall, 2004). Leading experts believe that these issues can be overcome but not in the near future unless technology development moves at light speed and cost structure decreases appreciably. Furthermore, tagging at the unit where 
companies are expected to reap the greatest benefits from their Supply Chain Management program must outweigh the tremendous current cost associated with RFID compliance.

\section{CONCLUSION}

RFIDs have tremendous opportunities for increasing value to a firm by providing increased product visibility, reduce out-of-stock items, trim warehouse costs, eliminate stock errors, reduce theft and shrinkage and allow companies to regularly update their logistics and inventory databases. Furthermore, it enables firms with such capability to remain competitive globally. Organizations such as retail giant Wal-Mart backed away from its rigid January 2005 RFID compliance deadline among its top 100 suppliers. Achieving this mark presented difficulties because RFID was still plagued by technological and operational difficulties. For instance, organizations must address issues regarding RFID command language, the presence of moisture, inclement weather, radiation, invisible RF interference (i.e., WLANs), attenuation, reflection and refraction of radio waves, the material to which a tag is affixed and to some extent building material content. Additionally, RFID operating standards do not exist for global operation, which would make tracing and tracking difficult for both import and export goods. Continued research needs to be carried before RFID can realize its full implementation at a reduced cost structure.

\section{REFERENCES}

1. Aberden Group (2004). www.aberdeen.com.

2. Bednarz, A., (2002). "Wireless Technology Reshapes Retailers", Network World, Framingham, v.19, Issue (32), p.23-24.

3. Bednarz, A., (2003). "Privacy Concerns Dog Initial RFID Plans", Network World, Framingham, v.20, Issue (17).

4. Bednarz, A., (2004). "Leeway found in Wal-Mart's RFID Mandate", Network World, Framingham, v.21, Issue (48).

5. $\quad$ Byrne, P., (2004). "Supply Chain RFID: Lesson Learned From a Leader", Logistics Management, Highland Ranch, v.43, Issue (5), p.31-33.

6. Fowler, D., (2003). "RFID Takes Stock of Supply Chain", Network World, Framingham, v.20, Issue (23).

7. Goldman, A. and Crawford, K., (2003). "Five Myths Exposed", Tech Centre, USA.

8. Hall, M., (2004) "Forget Wal-Mart", Computerworld, Framingham, v.38, Issue (51).

9. Hickey, K., (2003). "RFID Grew in 2002", Traffic World, Newark, p.20-21.

10. Kinsella, B., (2003). "The Wal-Mart Factor”, Industrial Engineer, Norcross, v.11, Issue (11), p.32-36.

11. Lawrence, D., (2004). "Tracking RFID Progress", American Printer, Chicago, v.232, Issue (4), p.16-17.

12. Spiegel, R., (2004). "RFID Report", Supply Chain Review Management Review, New York, v.8, Issue (4), p.62-63.

13. Sullivan, S., (2005). “The Plot Thickens”, Information Week, Issue (1020); p.24-27.

14. Tegtmeier, L.A. (2004). "RFID Knowledge Enabled Logistics; The Department of Defense is taking a different approach to RFID than Boeing's and Airbus' collaborative effort, but either way, the supply chain technology is coming fast", Overhaul and Maintenance, Washington, v.10, Issue (5).

15. Weisman, R., (2005). "Costs, Glitches Slow Wal-Mart Suppliers' Adoption of RFID”, The Boston Globe, Boston, MA, (January 2, 2005). 
NOTES 